\title{
International standards on return to work for social security institutions
}

\author{
Friedrich Mehrhoff \\ German Social Accident Insurance, Germany. friedrich.mehrhoff@dguv.de
}

The Guidelines on Return to Work and Reintegration of the International Social Security Association (ISSA) in Geneva published 2013 provides key-elements for successful disability management programs worldwide: Early intervention, personal-centred, work-place orientated, holistic-driven and multi-disciplined approach. Lots of tools and good practice from various countries and stakeholders in prevention and rehabilitation support the efforts of retaining and restore the employability of persons with disabilities within societies. The lecture offers an overview of the ISSA Guidelines and how they could be used as standard in social security institutions. 